\title{
Unique Approach of a Telemedicine System for CBD-Infused Foods
}

\author{
Namsoo Peter Kim ${ }^{1,2, * \mathbb{D}}$, Abhilash Aditya ${ }^{1} \mathbb{D}$, Hyun-jin Kang ${ }^{3}$ and Hee-Deung Park ${ }^{3,4}$ \\ 1 Department of Metallurgical Materials and Biomedical Engineering, The University of Texas, \\ El Paso, TX 79968, USA; aaditya@miners.utep.edu \\ 2 Brain Pool Fellow of Korea, Korea University, Seoul 02841, Korea \\ 3 School of Civil, Environmental and Architectural Engineering, Korea University, Seoul 02841, Korea; \\ kanghj84@gmail.com (H.-j.K.); heedeung@korea.ac.kr (H.-D.P.) \\ 4 KU-KIST Graduate School of Converging Science and Technology, Korea University, Seoul 02841, Korea \\ * Correspondence: nkim@utep.edu
}

Citation: Kim, N.P.; Aditya, A.; Kang, H.-j.; Park, H.-D. Unique Approach of a Telemedicine System for CBD-Infused Foods. Processes 2021, 9, 936. https://doi.org/ $10.3390 /$ pr9060936

Academic Editor: Won Byong Yoon

Received: 13 April 2021

Accepted: 21 May 2021

Published: 26 May 2021

Publisher's Note: MDPI stays neutral with regard to jurisdictional claims in published maps and institutional affiliations.

Copyright: (c) 2021 by the authors. Licensee MDPI, Basel, Switzerland. This article is an open access article distributed under the terms and conditions of the Creative Commons Attribution (CC BY) license (https:/ / creativecommons.org/licenses/by/ $4.0 /)$.

\begin{abstract}
As medical cannabis is legalized, food safety management systems, including CBD (cannabidiol), have received attention from scientific and engineering perspectives. Observations attribute CBD changes in acidic environments and high temperatures to THC (tetrahydrocannabinol). The current research focuses on employing and optimizing 3D printers, specifically material extrusion additive manufacturing processes for telemedicine applications to safely and accurately deliver CBD-infused food. Soft meat is prepared by supercritical $\mathrm{CO}_{2}\left(\mathrm{SC}-\mathrm{CO}_{2}\right)$ process and simultaneously infused with hemp oil for food printing. This study personalized the amount of CBD-infused food and analyzed its operating parameters based on a theoretical Hagen-Poiseuille equation and pressure drop. Head speed, direction change within a given time, pressure drops at tip or piston, the constant mass-flux in PTE (piston type extrusion), Vizo design (VD) with aesthetic elements, and head travel distance have been optimized. Between the University of Texas at El Paso in Texas, USA, and the Korea University in Seoul, Korea, repeated IoT system variable experiments through the web-cloud were limited to less than $1 \mathrm{~min}$, including print time. The telemedicine system was first tried and successfully performed using CBD-infused foods. During this process, images, G-code, video, and text, including medical descriptions, were provided simultaneously with CBD-infused food.
\end{abstract}

Keywords: cannabidiol (CBD); untact telemedicine; Hagen-Poiseuille (HP) equation; Vizo design (VD), piston-type extrusion (PTE); supercritical $\mathrm{CO}_{2}$ process $\left(\mathrm{SC}-\mathrm{CO}_{2}\right)$

\section{Introduction}

Due to the recent COVID-19 pandemic, the need for non-face-to-face contact or untact diagnosis has gained a rapid social response. There is a high need for remote treatment equipment for use with CBD (cannabidiol) to safely approve and track disease treatment methods. Results that have already been validated in WHO (World Health Organization) reports were submitted to the UN (United Nations) to legalize medical cannabis. Although the medical efficacy of CBD in childhood epilepsy and sleep disorders has been proven, the hallucinations, poisoning, national regulations, and clinical outcomes caused by THC (tetrahydrocannabinol) remain controversial. Going further, determining an acceptable amount of THC based on the pesticide component of a product and CBD activity is not an easy decision and requires more clinical discussion. This study does not cover any medical use or effectiveness of CBD and THC. The main focus is on the development and remote safety-testing of telemedicine equipment capable of quantitative distribution and tracking of CBD-infused food. When it comes to the use of CBD for medical purposes, some countries still need time to adapt to the UN amendments, and above all, there is social stigma and prejudices. However, recent research upholds the nutraceutical benefits of a food containing hemp, CBD, and THC to help people with medical conditions, including 
pain [1-3]. The telemedicine system would be used as a tool for the direct and active treatment by doctors', pharmacists, even on patients isolated from infectious diseases. It is particularly beneficial for patients with chronic diseases that require routine treatment, patients who are far away and it is inconvenient to go to the hospital, the elderly, or children who have difficulty swallowing special-type drugs. In general, telemedicine does not require hospitalization, but through continuous security such as monitoring the use of CBD and accumulate clinical data on the patient's symptoms, it is effective when different doses are required daily. This study is limited to delivery methods through effective telemedicine methods and operational optimization of those equipment based on the reported results.

The chemical properties of CBD have a melting point of 62 to $63{ }^{\circ} \mathrm{C}$, a solubility of $23.6 \mathrm{mg} / \mathrm{mL}$ in DMSO (Dimethyl sulfoxide) and ethanol, making it is easy to extract at high temperature and high pressure, or by ion extraction, solvent extraction, and supercritical extraction [4]. A research report suggested that $\mathrm{CBD}$ is destroyed or deformed in the case of high temperature [5]. To rule out this slight possibility, the $\mathrm{SC}-\mathrm{CO}_{2}$ process does not exceed $40{ }^{\circ} \mathrm{C}$ in preparing CBD-infused food. It has been demonstrated that the heating of CBD in some acidic solutions changes CBD to $\triangle-9-\mathrm{THC}$ [6]. How to convert CBD to other cannabinoids, including THC, is reported to have ambiguity and impurities [7]. Another area of interest is the self-conversion of CBD to THC. Given the limited evidence that CBD can be converted to $\triangle-9$-THC in the presence of acid, occurring in the human gut, in vitro studies have demonstrated this conversion potential using simulated gastric juice. One in vitro study reported a $2.9 \%$ formation conversion of $\Delta-9-\mathrm{THC}$ and other cannabinoid products in pepsin-free artificial gastric juice [8]. The formation of $\Delta-9-\mathrm{THC}$ and $\Delta-8$ THC when CBD was exposed to simulated gastric juice without enzymes at $37^{\circ} \mathrm{C}$ was reported. After CBD administration, there are also conflicting reports with little evidence that physiologically relevant effects and conversions of THC in humans occur in vivo after oral administration of CBD [9]. In other words, if the human gastric acidity is $\mathrm{pH} 3$ and the temperature is about $37^{\circ} \mathrm{C}$, the possibility of destruction of $\mathrm{CBD}$ in the human body or self-transformation to THC cannot be ignored. Telemedicine or 3D printing of fresh CBD for medical or edible use attracts attention as a field that can fundamentally control unnecessary oxidation [10]. To this end, this study applies telemedicine under conditions that guarantee the safety of CBD-infused foods according to acid-free, low temperature, and minimum exposure time which is valuable. It was concluded that there is no evidence that this modification occurs in humans after oral CBD administration. In a human study of volunteers, $600 \mathrm{mg}$ of CBD was administered to healthy participants, and no THC and trace amounts of THC metabolites were detected [11]. Similarly, chronic administration of CBD had no detectable THC. In a six-week clinical study of Huntington's disease patients who received $10 \mathrm{mg} / \mathrm{kg} /$ day of CBD (approximately $700 \mathrm{mg} /$ day) and the CBD plasma concentration range was 5.9 to $11.2 \mathrm{ng} / \mathrm{mL}$ without $\Delta-9 \mathrm{THC}$ [11]. If there is no internal conversion of CBD to THC, which causes hallucinations, the possibility of food administration beyond medical cannabis recommended by the United Nations can be expected. Further clinical studies are needed for this, and the study of the telemedicine system as a tool that provides basic data is needed promptly. When CBD is consumed with fat-containing foods, the absorption rate of CBD in blood increases by 4 to 14 times, or if $\mathrm{CBD}$ is packaged in aluminum cans, it is reported that the surface adsorption of $\mathrm{CBD}$ reduces or makes CBD unstable at high temperatures such as coffee [12-14]. Nevertheless, more research on $\mathrm{CBD}$ taken with food and systematic research are needed. Telemedicine technology is a new method that can be applied to CBD-infused food engineering in consideration of precision, speed, and hygienic material processing. A telemedicine study to minimize oxidation and transformation of CBD discussed above was needed [12-15].

Telemedicine devices are required that go beyond the capabilities of 3D printing technology. Three-dimensional food printing research suggests a new paradigm shift of the food production system where food for people with particular preferences needs specific care such as CBD-infused food [16]. It is a convergence of cutting-edge technologies, 
such as web-based and Internet of Things (IoT) technology, that prevents transmission of infectious diseases and control of ingredient technologies but ensures individuals' privacy. The problem of conventional 3D food printing is precise, but it is a limitation that various materials cannot be processed, and it takes at least $30 \mathrm{~min}$ to process $1000 \mathrm{~cm}^{3}$. The conventional 3D food printing process also has the potential for oxidation problems when handling CBD or foods containing it. Vizo design is an artform where a drawing is created with a single line and without retracing or overlapping the drawn line. The concept of VD enabled all printing to be completed within a maximum of one minute. The artist's handwriting and drawings were used as caricatures in order not to lose their artistry. The unique telemedicine system for the elderly and children who are reluctant to intake drugs with soft food was developed and tested. Systematic research on CBD-infused foods across the barrier of distance and time using a telemedicine system was implemented. The CBD-infused food printing technology developed from the untact concept consists of the $\mathrm{SC}-\mathrm{CO}_{2}$ of customized food materials, constant quantitative discharge, antioxidant and fast VD design, and web-based controls. All studies have used hemp oil, which is similar to CBD but approved for general consumption [17].

Korea University's K-CBD Center designs and uploads VD files with G code, video, and text through the website and stored in cloud because the legalization of the CBD for the Korean-US telemedicine law is different. CBD-infused food preparation, printing, and imaging were performed simultaneously at the University of Texas at El Paso's Printable Materials Certificate Center. Developing a method that transcends space is essential, and $\mathrm{CBD}$ is prescribed and delivered on-site. A specific method is to maximize untact synergy by controlling the e-platform provided by quantitative CBD through image, text, and G-code along with the introduction of an IoT-based telemedicine system [18-20]. Telemedicine systems and foods containing CBD can lead the 3D food market that can respond to global trends such as CBD burgers, CBD-infused drinks, CBD coffee, and 3D CBD sushi. Translating IoT and telemedicine technologies to real-time 3D food requires a paradigm shift to drive business, education, and art design. The best part is the reliability, reproducibility, economical operation, and quick maintenance to create 3D shapes.

COVID-19 has disrupted cafes, businesses, and education, which require face-to-face contact. The introduction of CBD-infused foods for untact printing integrates traditional food technology, IoT, AI, and telemedicine technologies. Telemedicine is an important technology in high-precision, rapid, hygienic processes with a sophisticated product performance and is an area that needs systematic research. It has been reported that highprecision piston-type extruder (PTE) technology provides an optimal printing method for telemedicine systems, providing a non-contagious environment and personalized vitaminC or CBD control $[16,21]$. To make the material printable, it must be in the form of a slurry as a gel material. Supercritical extraction of food ingredients has been selected as a useful technique that has also been used in purification and $\mathrm{CBD}$ extraction. The $\mathrm{SC}-\mathrm{CO}_{2}$ presents an optimal method for removing specific components such as residual blood or CBD purification in meat and has also been widely applied to CBD extraction [21]. The special advantage of the 3D printing technology is that it adopts high pressure to extrude high-viscosity food materials and then laminates directly layer by layer. This layering method promotes a high degree of sophistication and an artistic level of control over the meal $[18,22]$. Moreover, advanced nutrition and personalized controls provide significant benefits for individuals with specific allergies, ingredient management, telemedicine, or specific dietary habits [23]. The 3D food printing function can be used even at low temperatures, contributing to food antioxidants and energy-saving without prolonged heat or overheating. The factors used to drive the final result of this study are telemedicine foods containing CBD across time and distance barriers using IoT systems. The country-specific licensing for $\mathrm{CBD}$ and telemedicine equipment differs in different areas. No telemedicine equipment was used except for research purposes. Octoprint first reported data transmission via web and 3D printing control technology via open sources (https: / / octoprint.org/ (1 June 2019)) [24]. The concept of externally controlling printers through the web for 
telemedicine applications needs to be improved. Remote equipment control through internet in telemedicine enables secure two-way data transmission, print hardware use, and access to software that is 10 times faster than the existing 3D layer stacking process, which is easily downloaded from the cloud, and above all, ensures secure information delivery. Systems that enable video and text messages or on-site calls have been developed, and these systems have been used in CBD telemedicine systems.

\section{Materials and Methods}

Beef, chicken, mousse, cream cheese, yogurt, ketchup, jelly jam, coffee, eggs, hemp, and $\mathrm{CBD}$ oil were all purchased commercially. The $\mathrm{SC}-\mathrm{CO}_{2}$ was used to remove unwanted ingredients, and the newly added CBD oil was used for research purposes only. Chicken and beef were prepared using $5.00 \pm 0.50 \mathrm{~g}$ of each ingredient, then sealed in plastic bags and frozen at $-20^{\circ} \mathrm{C}$ to prevent the degradation of the CBD-infused materials before the experiment. The NINJA ${ }^{\circledR}$ model meat grinder was used to prepare printable chicken and beef at 6000 to 24,000 RPM in 5-min cycles. This cycle was repeated three times. To produce a printable material, the sample's largest chunk size must be less than $5.0 \times 10^{-5} \mathrm{~m}$. The amount of fat and CBD in food is controlled by the supercritical method, and the shape, flavor, and amount of CBD infusion in food are customized. Basic data were collected by extruding bread dough, meat, and other condiments, which included force exerted on the material discharge nozzle and viscosity change according to head speed. The fluidity characteristics of food and the maximum applicable pressure are summarized in Table 1.

Table 1. Fluid and hydrodynamic properties of food ingredients and applied pressure [16,21].

\begin{tabular}{ccccccccc}
\hline Materials & Jam & Ketchup & $\begin{array}{c}\text { Peanut } \\
\text { Butter }\end{array}$ & Pudding & CBD Oil $^{\text {Mayo }}$ & SC-CO $_{2}$ Beef & $\begin{array}{c}\text { SC-CO } \\
\text { Chicken }\end{array}$ \\
\hline Viscosity (Pa-s) & $10-100$ & $75-100$ & $250-1000$ & $10-100$ & $5-100$ & $5-100$ & $1200-15,000$ & $800-12,000$ \\
Density (g/cm $\left.{ }^{3}\right)$ & 0.96 & 0.94 & 1.06 & 1.27 & $0.9-1.1$ & 1.03 & $1.0-1.2$ & $0.98-1.23$ \\
Maximum & 0.145 & 0.432 & 1.205 & 0.145 & 0.25 & 0.123 & 1.84 & 1.82 \\
Pressure (MPa) & & & & & & & & \\
\hline
\end{tabular}

Baseline data was acquired through various onboard pressure and motion sensors by running the printer without the build material. The acquired data was crucial for optimizing the printer to print food material that exhibited non-Newtonian behavior. Rhinoceros 3D, a computer-aided designing software, was used to create customized designs, and CURA, an open-source $\mathrm{G}$ code generator, was used to aid the coordinates for $3 \mathrm{D}$ food printing. The 3D printer can print CBD-infused food, also just CBD or hemp oil, over other food with extreme precision.

IoT-controlled CBD food printing systems are particularly advantageous for personalized telemedicine by controlling food ingredient distribution more accurately than traditional cooking processes as detailed in Figure 1 below. In particular, the Raspberry Pi (3B Plus) accepts the encrypted design data through the internet, and the Arduino (MEGA 2650) controls the nozzle movement designed in the same space with a sophisticated 2D or 3D printing capability, as shown in Figure 1. The designs were uploaded to the cloud by using a device with an internet connection, and the IoT-enabled 3D printer accesses the uploaded design for printing.

For the concept of equipment control through the internet (web/cloud), a new system was first attempted in which remote practice, secure two-way data transmission, and VD files that can be printed within 1 min can convey personal videos and texts-a web program that anyone can easily download and use. This paper describes the experimental conditions for applied variables that are not described in the patent [25]. 


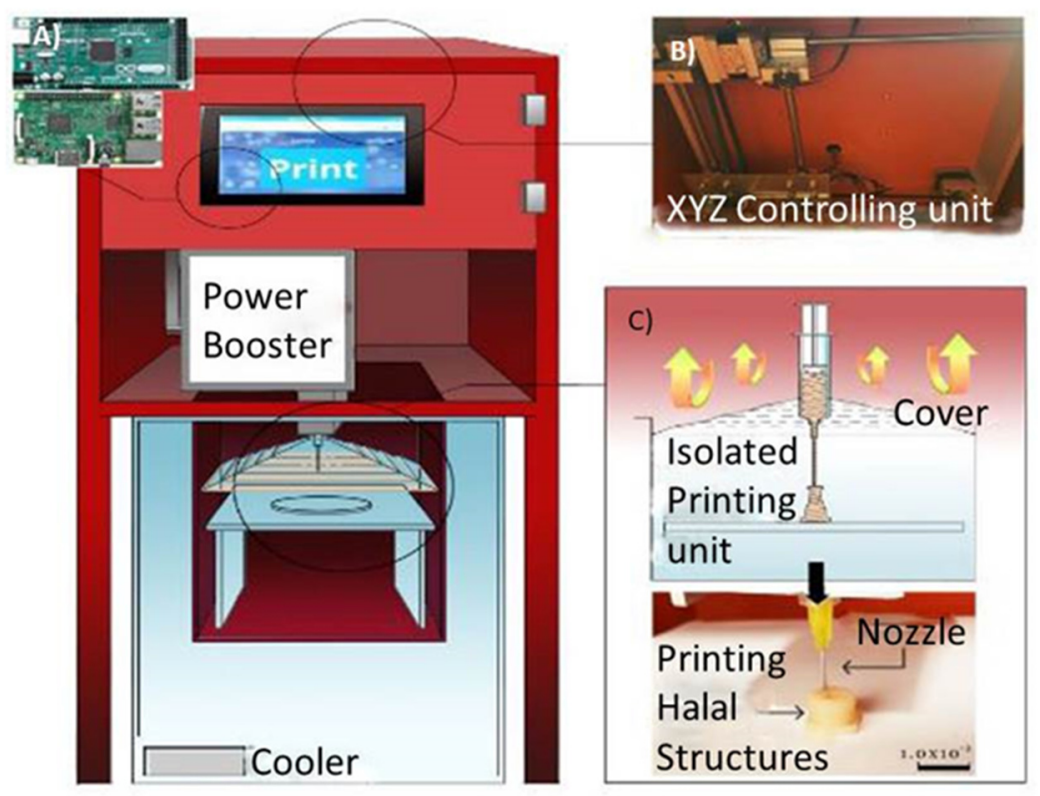

Figure 1. Conceptual drawing of a non-face-to-face contact web-based IoT food printer (A): Raspberry Pi receiving the printing code from the outside and the Arduino board mounted at the same time (B); unique printing $X Y Z$ control system equipped with a monkey-bar head on the ceiling for precise food control. (C) For clean food printing, negative pressure is applied to the outside of the printing chamber.

\section{Results and Discussion}

\subsection{SC-CO $\mathrm{CO}_{2}$ of ustomized Food Materials}

In general, it is known that the SC- $\mathrm{CO}_{2}$ of extracting hemp does not significantly affect CBD's stability. Therefore, the mixed supercritical extraction of fat and CBD and co-precipitation parameters were optimized to determine the optimal telemedicine possible factor. It has been reported that the absorption rate of CBD in blood and the amount of fat in food are closely related. In addition to CBD, it is a technology to make ingredients that can print customized materials replacing harmful components by adding healthy ingredients such as ginseng, garlic, and ginger. Most of the supercritical processes use carbon dioxide gas, and such processed foods for controlling ingredients remain porridgelike in shape [26-30]. In these porridges, the size of the solid material is less than $100 \mu \mathrm{m}$ in diameter, and personalized food is possible to print with telemedicine if the moisture content is suitably adjusted. The supercritical method of controlling the amount of animalbased or vegetable fat in food using co-solvent for meat, beef, pork, and vegetables is closely related to the absorption rate of CBD. In the supercritical method, a three-dimensional shape was successfully prepared and the fat and CBD components of the food were adjusted. The absorption rate of CBD, in combination with various foods, has not been reported in detail. This study provides a method for systematically providing fundamental data, and the absorption rate in animals or humans is not covered. In the case of CBD-infused coffee, to increase the amount of foam the hot coffee passed through the cold foam containing air and was printed with the optimum foam thickness that does not transfer heat to the printed CBD-containing material.

\subsection{Constant Quantitative Discharge}

The sustained quantitative release of CBD-infused foods is the most crucial factor in adjusting the final content of CBD. CBD-infused foods with precisely controlled ingredients are used as telemedicine systems. By changing the solubility, it can be used with various vegetable oils, beef, pork, and chicken. At this time, the mixing conditions of fat and CBD were used to maximize the entropy mixing effect in consideration of components, especially fat components, and optimal medical applicability. Through $\mathrm{SC}-\mathrm{CO}_{2}$ extraction, a rapid and 
non-toxic purification process was applied to obtain high-quality, personalized 3D printable CBD food. Halal food is regarded as healthy food without religious prejudice [31-35]. SC$\mathrm{CO}_{2}$ chicken and beef are blended with CBD-infused vegetables, known as a healthy recipe within $\pm 0.5 \mathrm{wt} \%$ of error [25,36-39]. The 3D structure of personalized food has been successfully built while preserving the initial ingredients, antioxidants, hygiene, and freshness. Specifically, for quantitative analysis, the tip size has been optimized from $1.1 \times 10^{-4} \mathrm{~m}$ to $7.2 \times 10^{-3} \mathrm{~m}$ to understand the constant flow rate relationship between PTE parameters and IoT control G-code head-traveling speed [21]. The material refill comes in an assembly of a cylindrical tube with a piston. This provides the 3D printer with a simple change of material and cleaning mechanism.

\subsection{Concept and Application of Telemedicine, Including CBD}

The commercially available sample materials, meat, and hemp oils were prepared to analyze the effect of printability of products. The beef was ground and then mixed with hemp oils, as seen in Figure 2. Many studies have tried to print cookies, dressings, and small meals, and recently there have been attempts to print desserts or portions of food in restaurants or even print sushi in Japan [40]. Still, most of all, printing consumes more than $30 \mathrm{~min}$ for a $1000 \mathrm{~cm}^{3}$ size of stratus. This study conducted several experiments to print the world's smallest cheeseburger to contain CBD, including making sushi with $\mathrm{SC}-\mathrm{CO}_{2}$ fish and beef and chicken food with $\mathrm{SC}-\mathrm{CO}_{2}$. Untact telemedicine requires a specific skill set while preparing food with custom ingredients. Infusing medicine in food and printing in an artistic manner is visually appealing and is possible through the proposed 3D printing technology. The possibility of numerous design customization helps the patients to see the medication as more appetizing rather than to express common hesitation. The telemedicine system is primarily helpful for children, the elderly, and the socially vulnerable in remote rural areas. A new idea was put forth for those who have difficulty swallowing pills to treat chronic conditions, those who are uncomfortable with the powder, or those who know they are healthy but cannot take them due to their smell, such as fish $[32,35]$. This method is necessary for non-face-to-face contact with nutrient products such as carbohydrates, vitamins, fiber, and infused foods, which people with diabetes should monitor while consuming, and those with high blood pressure, allergies, or chronic conditions $[9,32]$. Residual blood, fat, and cholesterol are extracted from beef, and then CBD is infused to make 3D sushi-style food made from meat. Cookies made with somebody's face-shape, ice cream and egg coffee, the Eiffel Tower shape made from chicken, and the salad dressing that consumers imagined could all contain CBD. Despite the trend of legalizing CBD worldwide, it is undeniable that it is extracted from marijuana, an inconvenient truth. It is effective against tics, sleep disorders, pain relievers, panic disorders, but as shown in Figure 2, the general use of CBD is not active. This study is based on the preparation of food using a telemedicine system that can be prepared as desired. It was confirmed that reliable remote delivery might be as important as the drug's effectiveness. Telemedicine makes it possible for medical hemp to enable two-way communication with patients, and doctors continuously analyze specific information about the disease through continuous data accumulation, even in the treatment of individual conditions. Various methods, such as the quantification of CBD and mixing with other drugs, are performed. Research shows the medical benefit of CBD in treating patients with chronic pain, refractory seizures, anxiety, schizophrenia, and more [41]. In Figure 2A below, panic, sleep disturbance, epilepsy, or tics patients with untact contact delivery systems are described in detail. In Figure 2B, the structural formula of CBD is shown. All shapes were printed in less than $1 \mathrm{~min}$. In Figure 2C, CBD-infused chocolate syrup on coffee is illustrated in the form of 2D printing, indicating that it can be applied to the sleeping disorders of the elderly. Printing was successful using CBD oil directly on coffee (Figure 2D). 

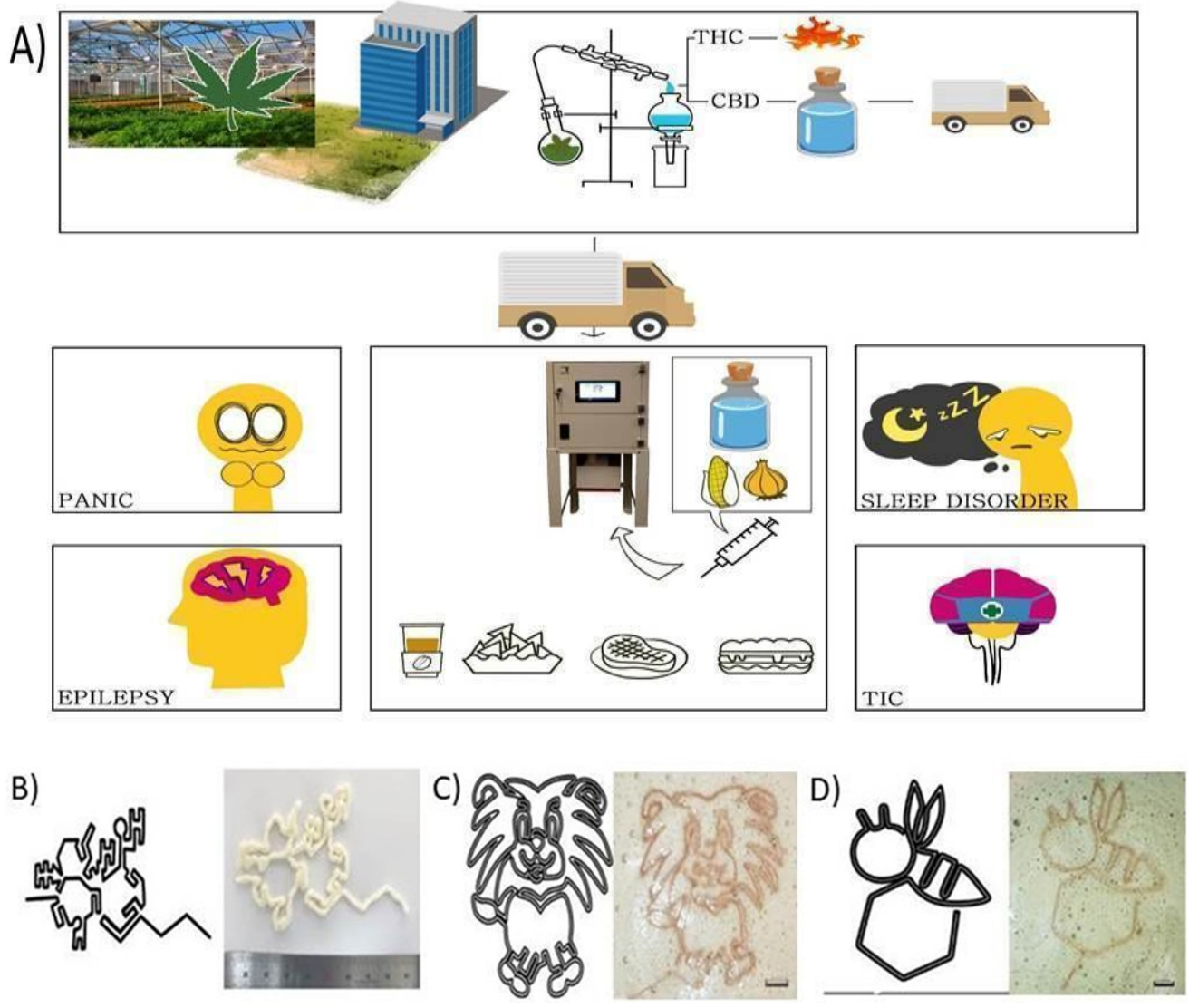

Figure 2. Conceptual diagrams and results where purified CBD extracted for non-face-to-face contact are delivered remotely, mixed with food, and delivered to the user; (A) a non-face-to-face contact CBD delivery system concept to treat patients dealing with panic, sleep disorder, epilepsy, or tics; (B) chemical structural formula of CBD and printed food with CBD-infused ice cream; (C) 2D printing shape of CBD-infused chocolate syrup on coffee (D) the printed form of direct CBD oil dispensed on coffee.

\subsection{Parameter Control for Quantitative Discharge}

The constant viscosity fluid dynamic behavior consistent with the shear rate changes was monitored to adjust the constant velocity of the material at a force of $170 \mathrm{~N}$, the highest pressure the equipment can exert for the high viscosity of food. The Hagen-Poiseuille (HP) equation was used for constant flow control for non-Newtonian food.

$$
q_{w}=\frac{\pi r^{4} \Delta P \rho}{8 \mu L}
$$

The HP equation used in the process is shown above where $q_{w}=$ mass flow rate $(\mathrm{g} / \mathrm{s})$, $r=$ internal radius of the piston nozzle $(\mathrm{m}), \Delta P=$ pressure drop $(\mathrm{Pa}), \rho=$ density of foods $\left(\mathrm{g} / \mathrm{cm}^{3}\right), \mu=$ dynamic fluid viscosity $(\mathrm{Pa} \cdot \mathrm{s})$, and $\mathrm{L}=$ length of the piston nozzle $(\mathrm{m})$.

The pressure was tested based on the optimized experiment by maintaining the change in the discharge flow rate $\left(q_{w}\right)$ in the steady-state, up to $180 \mathrm{~s}$ after $1 \mathrm{~s}$ from the initiation. In theory, based on many existing experiments, it is enough to overcome the total pressure drop ( $\left.\triangle P_{\text {Total }}\right)$, consisting of three components to control the PTE quantitatively. It is the sum of pressure drops at the rubber-to-inner wall of the piston itself $\left(\Delta P_{\text {Friction }}\right)$, the resistance of the nozzle tip to the filler material $\left(\Delta P_{\text {Tip }}\right)$, and the resistance of the filler material to the inner wall of the piston $\left(\Delta P_{\text {Piston }}\right)$. Among the many variables, it is best to repeatedly experiment with a variable that has a considerable influence and a variable that does not affect the material or a variable that does not affect the material in the maintenance of a constant velocity of pressure delivery. The discharges were controlled in real-time 
through an onboard Raspberry Pi computer system. The pressure sensors at the piston and the weight sensor at the build platform feed the total pressure drop and weight to the Raspberry Pi in real-time, and the HP equation calculates the relevant pressure drops with the discharged material weight.

The experimental results below are summarized in Table 2 and are useful for providing the best quantitative discharge basis.

Table 2. Data on the discharge of air and hemp-oil volume and pressure intensification experiment results according to tip size and press speed (velocity of the press).

\begin{tabular}{|c|c|c|c|c|c|c|c|c|c|c|}
\hline & $\begin{array}{c}\text { Velocity } \\
\text { of Press } \\
(\mathrm{m} / \mathrm{s})\end{array}$ & $\begin{array}{l}\text { Tip Size } \\
\text { (m) }\end{array}$ & $\begin{array}{l}\text { Shear } \\
\text { Rate } \\
\left(s^{-1}\right)\end{array}$ & $\begin{array}{l}\Delta P_{\text {Friction }} \\
\quad(\mathrm{Pa})\end{array}$ & $\begin{array}{c}\text { STDEV } \\
\text { of } \\
\Delta P_{\text {Friction }}\end{array}$ & $\begin{array}{c}\Delta P_{\mathrm{Tip}} \\
(\mathrm{Pa})\end{array}$ & $\begin{array}{l}\text { STDEV } \\
\text { of } \Delta P_{\text {Tip }}\end{array}$ & $\begin{array}{l}\Delta P_{\text {Piston }} \\
\quad(\mathbf{P a})\end{array}$ & $\underset{\left(\mathrm{m}^{3} / \mathrm{s}\right)}{\mathrm{qu}_{\mathrm{v}}}$ & $\begin{array}{l}\text { STDEV } \\
\text { of } \mathrm{q}_{\mathrm{v}}\end{array}$ \\
\hline \multirow{24}{*}{ Air } & $8.33 \mathrm{E}-05$ & $4.00 \mathrm{E}-04$ & $2.99 \mathrm{E}+02$ & $2.39 \mathrm{E}+04$ & $1.83 \mathrm{E}+03$ & $4.06 \mathrm{E}-01$ & $2.20 \mathrm{E}-01$ & $1.47 \mathrm{E}-05$ & $1.50 \mathrm{E}-08$ & $8.16 \mathrm{E}-09$ \\
\hline & $8.33 \mathrm{E}-05$ & $2.00 \mathrm{E}-04$ & $2.34 \mathrm{E}+03$ & $2.67 \mathrm{E}+04$ & $2.32 \mathrm{E}+03$ & $6.39 \mathrm{E}+00$ & $2.69 \mathrm{E}+00$ & $1.44 \mathrm{E}-05$ & $1.47 \mathrm{E}-08$ & $6.22 \mathrm{E}-09$ \\
\hline & $8.33 \mathrm{E}-05$ & $1.10 \mathrm{E}-04$ & $1.43 \mathrm{E}+04$ & $2.88 \mathrm{E}+04$ & $2.60 \mathrm{E}+03$ & $7.04 \mathrm{E}+01$ & 3.37E+01 & $1.45 \mathrm{E}-05$ & $1.49 \mathrm{E}-08$ & $7.13 E-09$ \\
\hline & $8.33 \mathrm{E}-05$ & $7.50 \mathrm{E}-05$ & $4.49 \mathrm{E}+04$ & $3.04 \mathrm{E}+04$ & $1.41 \mathrm{E}+03$ & $3.25 \mathrm{E}+02$ & $1.49 \mathrm{E}+02$ & $1.45 \mathrm{E}-05$ & $1.49 \mathrm{E}-08$ & $6.81 \mathrm{E}-09$ \\
\hline & $1.67 \mathrm{E}-04$ & $7.50 \mathrm{E}-04$ & $2.94 \mathrm{E}+02$ & $4.19 \mathrm{E}+04$ & None & $2.13 \mathrm{E}-01$ & None & $9.47 \mathrm{E}-05$ & $9.73 \mathrm{E}-08$ & None \\
\hline & $3.33 \mathrm{E}-04$ & $7.50 \mathrm{E}-04$ & $5.81 \mathrm{E}+02$ & $3.62 \mathrm{E}+04$ & None & $4.21 \mathrm{E}-01$ & None & $1.88 \mathrm{E}-04$ & $1.93 \mathrm{E}-07$ & None \\
\hline & $5.00 \mathrm{E}-04$ & $7.50 \mathrm{E}-04$ & $8.72 \mathrm{E}+02$ & $2.98 \mathrm{E}+04$ & None & $6.31 \mathrm{E}-01$ & None & $2.81 \mathrm{E}-04$ & $2.89 \mathrm{E}-07$ & None \\
\hline & $6.67 \mathrm{E}-04$ & $7.50 \mathrm{E}-04$ & $1.14 \mathrm{E}+03$ & $1.99 \mathrm{E}+04$ & None & $8.26 \mathrm{E}-01$ & None & $3.68 \mathrm{E}-04$ & $3.78 \mathrm{E}-07$ & None \\
\hline & $8.33 \mathrm{E}-04$ & $1.00 \mathrm{E}-03$ & $1.90 \mathrm{E}+01$ & $1.55 \mathrm{E}+04$ & $9.20 \mathrm{E}+02$ & $1.03 \mathrm{E}-02$ & $1.03 \mathrm{E}-02$ & $1.46 \mathrm{E}-05$ & $1.49 \mathrm{E}-08$ & $7.40 \mathrm{E}-09$ \\
\hline & $8.33 \mathrm{E}-04$ & $7.50 \mathrm{E}-04$ & $4.52 \mathrm{E}+01$ & $2.07 \mathrm{E}+04$ & $1.41 \mathrm{E}+03$ & $3.27 \mathrm{E}-02$ & $1.63 \mathrm{E}-02$ & $1.46 \mathrm{E}-05$ & $1.50 \mathrm{E}-08$ & $7.44 \mathrm{E}-09$ \\
\hline & $8.33 \mathrm{E}-04$ & $1.00 \mathrm{E}-03$ & $1.83 \mathrm{E}+02$ & $1.44 \mathrm{E}+04$ & $1.85 \mathrm{E}+03$ & $9.93 \mathrm{E}-02$ & $7.58 \mathrm{E}-03$ & $1.40 \mathrm{E}-04$ & $1.44 \mathrm{E}-07$ & $1.10 \mathrm{E}-08$ \\
\hline & $8.33 \mathrm{E}-04$ & $7.50 \mathrm{E}-04$ & $4.32 \mathrm{E}+02$ & $2.08 \mathrm{E}+04$ & $1.30 \mathrm{E}+03$ & $3.13 \mathrm{E}-01$ & $2.32 \mathrm{E}-02$ & $1.40 \mathrm{E}-04$ & $1.43 \mathrm{E}-07$ & $1.06 \mathrm{E}-08$ \\
\hline & $8.33 \mathrm{E}-04$ & $7.50 \mathrm{E}-04$ & $1.41 \mathrm{E}+03$ & $1.90 \mathrm{E}+04$ & None & $1.02 \mathrm{E}+00$ & None & $4.56 \mathrm{E}-04$ & $4.68 \mathrm{E}-07$ & None \\
\hline & $8.33 \mathrm{E}-04$ & $4.00 \mathrm{E}-04$ & $2.86 \mathrm{E}+03$ & $2.13 \mathrm{E}+04$ & $1.35 \mathrm{E}+03$ & $3.88 \mathrm{E}+00$ & $3.17 \mathrm{E}-01$ & $1.40 \mathrm{E}-04$ & $1.44 \mathrm{E}-07$ & $1.17 \mathrm{E}-08$ \\
\hline & $8.33 \mathrm{E}-04$ & $2.00 \mathrm{E}-04$ & $2.28 \mathrm{E}+04$ & $2.50 \mathrm{E}+04$ & $1.58 \mathrm{E}+03$ & $6.20 \mathrm{E}+01$ & $4.91 \mathrm{E}+00$ & $1.40 \mathrm{E}-04$ & $1.44 \mathrm{E}-07$ & $1.14 \mathrm{E}-08$ \\
\hline & $8.33 \mathrm{E}-04$ & $1.10 \mathrm{E}-04$ & $1.38 \mathrm{E}+05$ & $2.90 \mathrm{E}+04$ & $1.92 \mathrm{E}+03$ & $6.80 \mathrm{E}+02$ & $6.15 \mathrm{E}+01$ & $1.40 \mathrm{E}-04$ & $1.44 \mathrm{E}-07$ & $1.30 \mathrm{E}-08$ \\
\hline & $1.67 \mathrm{E}-03$ & $7.50 \mathrm{E}-04$ & $8.58 \mathrm{E}+02$ & $2.96 \mathrm{E}+04$ & $1.28 \mathrm{E}+03$ & $1.00 \mathrm{E}+00$ & $0.00 \mathrm{E}+00$ & $2.77 \mathrm{E}-04$ & $2.84 \mathrm{E}-07$ & $9.92 \mathrm{E}-09$ \\
\hline & $1.67 \mathrm{E}-03$ & $4.00 \mathrm{E}-04$ & $5.66 \mathrm{E}+03$ & $2.94 \mathrm{E}+04$ & $8.92 \mathrm{E}+02$ & $8.00 \mathrm{E}+00$ & $0.00 \mathrm{E}+00$ & $2.77 \mathrm{E}-04$ & $2.84 \mathrm{E}-07$ & $1.01 \mathrm{E}-08$ \\
\hline & $1.67 \mathrm{E}-03$ & $2.00 \mathrm{E}-04$ & $4.51 \mathrm{E}+04$ & $2.61 E+04$ & $1.40 \mathrm{E}+03$ & $1.23 \mathrm{E}+02$ & $4.00 \mathrm{E}+00$ & $2.76 \mathrm{E}-04$ & $2.83 \mathrm{E}-07$ & $8.83 \mathrm{E}-09$ \\
\hline & $1.67 \mathrm{E}-03$ & $1.10 \mathrm{E}-04$ & $2.75 \mathrm{E}+05$ & $3.41 \mathrm{E}+04$ & $1.16 \mathrm{E}+03$ & $1.36 \mathrm{E}+03$ & $5.40 \mathrm{E}+01$ & $2.80 \mathrm{E}-04$ & $2.87 \mathrm{E}-07$ & $1.14 \mathrm{E}-08$ \\
\hline & $3.33 \mathrm{E}-03$ & $7.50 \mathrm{E}-04$ & $1.67 \mathrm{E}+03$ & $3.14 \mathrm{E}+04$ & $5.37 \mathrm{E}+02$ & $1.21 \mathrm{E}+00$ & $2.76 \mathrm{E}-02$ & $5.40 \mathrm{E}-04$ & $5.55 \mathrm{E}-07$ & $1.26 \mathrm{E}-08$ \\
\hline & $3.33 E-03$ & $4.00 \mathrm{E}-04$ & $1.10 \mathrm{E}+04$ & $3.47 \mathrm{E}+04$ & $9.43 \mathrm{E}+02$ & $1.49 \mathrm{E}+01$ & $4.43 \mathrm{E}-01$ & $5.38 \mathrm{E}-04$ & $5.53 \mathrm{E}-07$ & $1.64 \mathrm{E}-08$ \\
\hline & $3.33 \mathrm{E}-03$ & $2.00 \mathrm{E}-04$ & $8.83 \mathrm{E}+04$ & $3.31 \mathrm{E}+04$ & $5.14 \mathrm{E}+02$ & $2.40 \mathrm{E}+02$ & $5.68 \mathrm{E}+00$ & $5.40 \mathrm{E}-04$ & $5.55 \mathrm{E}-07$ & $1.31 \mathrm{E}-08$ \\
\hline & $3.33 \mathrm{E}-03$ & $1.10 \mathrm{E}-04$ & $5.33 \mathrm{E}+05$ & $4.49 \mathrm{E}+04$ & $8.73 \mathrm{E}+03$ & $2.63 \mathrm{E}+03$ & $4.58 \mathrm{E}+01$ & $5.42 \mathrm{E}-04$ & $5.57 \mathrm{E}-07$ & $9.70 \mathrm{E}-09$ \\
\hline \multirow{16}{*}{ Oil } & $8.33 E-05$ & $2.00 \mathrm{E}-04$ & $2.31 E+03$ & $2.62 \mathrm{E}+04$ & $4.68 \mathrm{E}+03$ & $1.04 \mathrm{E}+04$ & $5.62 \mathrm{E}+02$ & $2.10 \mathrm{E}-02$ & $1.45 \mathrm{E}-08$ & $7.85 \mathrm{E}-10$ \\
\hline & $8.33 \mathrm{E}-05$ & $4.00 \mathrm{E}-04$ & $3.00 \mathrm{E}+02$ & $9.70 \mathrm{E}+03$ & $1.02 \mathrm{E}+03$ & $6.76 \mathrm{E}+02$ & $4.76 \mathrm{E}+01$ & $2.19 \mathrm{E}-02$ & $1.51 \mathrm{E}-08$ & $1.06 \mathrm{E}-09$ \\
\hline & $8.33 E-05$ & $7.50 \mathrm{E}-04$ & $4.48 \mathrm{E}+01$ & $7.98 \mathrm{E}+03$ & $5.08 \mathrm{E}+02$ & $5.38 \mathrm{E}+01$ & $1.25 \mathrm{E}+00$ & $2.15 \mathrm{E}-02$ & $1.49 \mathrm{E}-08$ & $3.44 \mathrm{E}-10$ \\
\hline & $8.33 \mathrm{E}-05$ & $1.00 \mathrm{E}-03$ & $1.90 \mathrm{E}+01$ & $6.61 \mathrm{E}+03$ & $5.83 \mathrm{E}+02$ & $1.71 \mathrm{E}+01$ & $5.86 \mathrm{E}-01$ & $2.16 \mathrm{E}-02$ & $1.49 \mathrm{E}-08$ & $5.12 \mathrm{E}-10$ \\
\hline & $8.33 \mathrm{E}-04$ & $2.00 \mathrm{E}-04$ & $2.19 \mathrm{E}+04$ & $9.03 \mathrm{E}+04$ & $2.79 E+04$ & $9.86 \mathrm{E}+04$ & $3.37 \mathrm{E}+03$ & $2.22 \mathrm{E}-01$ & $1.38 \mathrm{E}-07$ & $4.71 \mathrm{E}-09$ \\
\hline & $8.33 \mathrm{E}-04$ & $4.00 \mathrm{E}-04$ & $2.70 \mathrm{E}+03$ & $3.82 \mathrm{E}+04$ & $4.83 \mathrm{E}+03$ & $6.08 \mathrm{E}+03$ & $4.00 \mathrm{E}+02$ & $2.19 \mathrm{E}-01$ & $1.36 \mathrm{E}-07$ & $8.94 \mathrm{E}-09$ \\
\hline & $8.33 \mathrm{E}-04$ & $7.50 \mathrm{E}-04$ & $4.13 \mathrm{E}+02$ & $2.53 \mathrm{E}+04$ & $3.97 \mathrm{E}+03$ & $4.95 \mathrm{E}+02$ & $2.48 \mathrm{E}+01$ & $2.21 \mathrm{E}-01$ & $1.37 \mathrm{E}-07$ & $6.85 \mathrm{E}-09$ \\
\hline & $8.33 \mathrm{E}-04$ & $1.00 \mathrm{E}-03$ & $1.74 \mathrm{E}+02$ & $2.18 \mathrm{E}+04$ & $3.65 \mathrm{E}+03$ & $1.57 \mathrm{E}+02$ & $7.29 \mathrm{E}+00$ & $2.21 \mathrm{E}-01$ & $6.36 \mathrm{E}-09$ & $6.36 \mathrm{E}-09$ \\
\hline & 1.67E-03 & $2.00 \mathrm{E}-04$ & $4.32 \mathrm{E}+04$ & $2.38 \mathrm{E}+05$ & $3.50 \mathrm{E}+04$ & $1.94 \mathrm{E}+05$ & 1.47E+04 & 4.37E-01 & 2.71E-07 & $1.58 \mathrm{E}-08$ \\
\hline & $1.67 \mathrm{E}-03$ & $4.00 \mathrm{E}-04$ & $5.43 \mathrm{E}+03$ & $5.40 \mathrm{E}+04$ & $3.44 \mathrm{E}+03$ & $1.22 \mathrm{E}+04$ & $6.83 \mathrm{E}+02$ & $4.40 \mathrm{E}-01$ & $2.73 \mathrm{E}-07$ & $1.53 \mathrm{E}-08$ \\
\hline & $1.67 \mathrm{E}-03$ & $7.50 \mathrm{E}-04$ & $8.24 \mathrm{E}+02$ & $6.52 \mathrm{E}+04$ & $3.91 E+03$ & $9.88 \mathrm{E}+02$ & $5.53 \mathrm{E}+01$ & $4.40 \mathrm{E}-01$ & $2.73 \mathrm{E}-07$ & $1.53 \mathrm{E}-08$ \\
\hline & $1.67 \mathrm{E}-03$ & $1.00 \mathrm{E}-03$ & $3.46 \mathrm{E}+02$ & $2.44 \mathrm{E}+04$ & $3.34 \mathrm{E}+03$ & $3.09 \mathrm{E}+02$ & $3.63 E+01$ & $4.39 \mathrm{E}-01$ & $1.72 \mathrm{E}-08$ & $1.72 \mathrm{E}-08$ \\
\hline & $3.33 \mathrm{E}-03$ & $2.00 \mathrm{E}-04$ & $8.61 \mathrm{E}+04$ & $4.50 \mathrm{E}+05$ & $6.54 \mathrm{E}+04$ & $3.86 \mathrm{E}+05$ & $3.15 \mathrm{E}+04$ & $8.70 \mathrm{E}-01$ & $5.41 \mathrm{E}-07$ & $4.39 \mathrm{E}-08$ \\
\hline & $3.33 \mathrm{E}-03$ & $4.00 \mathrm{E}-04$ & $1.08 \mathrm{E}+04$ & $9.46 \mathrm{E}+04$ & $1.11 \mathrm{E}+04$ & $2.42 \mathrm{E}+04$ & $1.76 \mathrm{E}+03$ & $8.73 \mathrm{E}-01$ & $5.41 \mathrm{E}-07$ & $3.93 \mathrm{E}-08$ \\
\hline & $3.33 \mathrm{E}-03$ & $7.50 \mathrm{E}-04$ & $1.63 \mathrm{E}+03$ & $4.71 \mathrm{E}+04$ & $5.31 E+03$ & $1.96 \mathrm{E}+03$ & $1.41 \mathrm{E}+02$ & $8.73 \mathrm{E}-01$ & $5.41 \mathrm{E}-07$ & $3.91 \mathrm{E}-08$ \\
\hline & $3.33 E-03$ & $1.00 \mathrm{E}-03$ & $6.88 \mathrm{E}+02$ & $5.33 \mathrm{E}+04$ & $7.55 \mathrm{E}+03$ & $6.19 \mathrm{E}+02$ & $6.19 \mathrm{E}+02$ & $8.72 \mathrm{E}-01$ & $5.40 \mathrm{E}-07$ & $4.07 \mathrm{E}-08$ \\
\hline
\end{tabular}

It was observed that a piston filled with air without material could be discharged quantitatively with a force lesser than $5 \mathrm{~N}$, as shown in Figure 3 below. It was confirmed that the pressure drop due to the frictional force of the equipment, $\Delta P_{\text {Friction }}$ was the main factor in the discharge of the material at all shear rates for printing. In other words, the pressure drops, $\Delta P_{\text {Tip }}$ and $\Delta P_{\text {Piston }}$ does not affect compared to $\Delta P_{\text {Friction }}$ where printing is 
possible even with a high shear rate pressing the air (Figure 3, left). However, in Figure 3 (right), in which the piston was filled with hemp oil, an interesting fact was discovered, and repeated experiments were implemented. In the case of hemp oil, it has a relatively higher viscosity than air. When the shear rate is increased by the increased compression speed of the material, the pressure drop at the nozzle tip ( $\left.\Delta P_{\text {Tip }}\right)$ of the material is compared with the $\Delta P_{\text {Friction }}$ of the equipment. It has also been confirmed that it reached a level that cannot be ignored. If the shear stress was increased, the $\Delta P_{\text {Friction }}$ of the equipment increased finely, but rather, the increase in $\Delta P_{\text {Tip }}$ of the material increased exponentially, which can exceed the $\Delta P_{\text {Friction }}$ of the equipment. In this case, the PTE does not have the equipment to supply more than $170 \mathrm{~N}$ smoothly, so an additional pressure booster was required for this, and the stability of the piston itself could not be verified. Therefore, based on the HP theory equation, the tip size is inversely proportional to the pressure drop to the 4th power of the radius, and it is predicted that it can perform much more sensitively than the equipment Delphi, which is the result of the above experiment, so the pressure drop according to the tip size was tested.
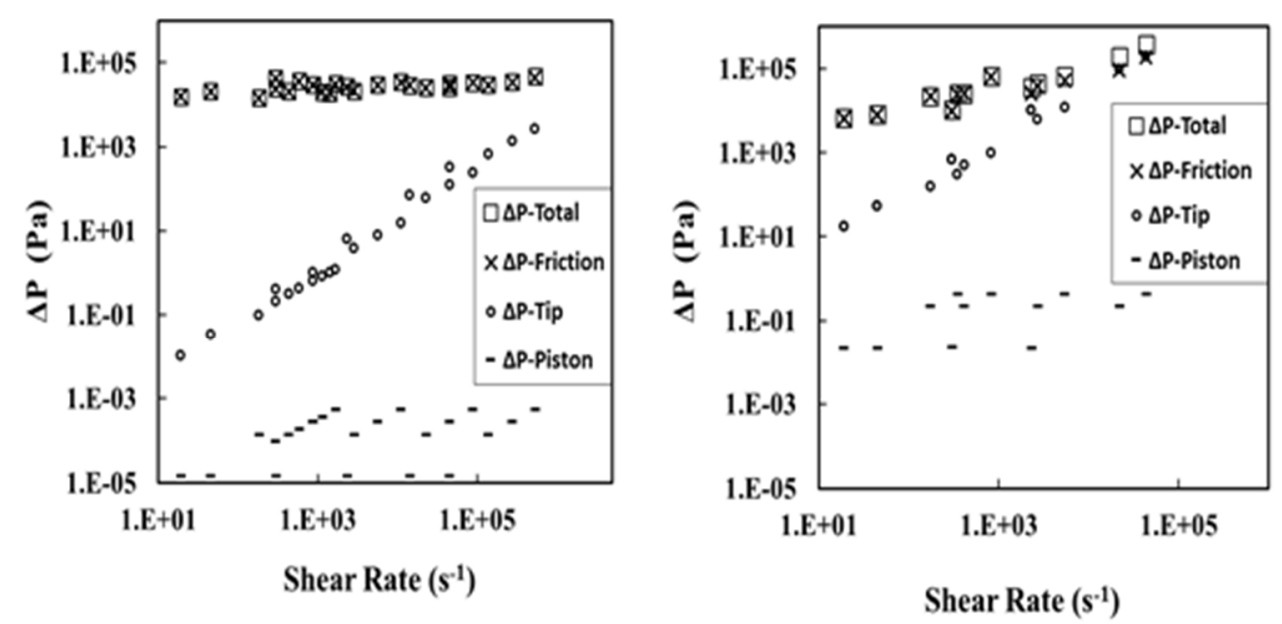

Figure 3. Pressure drop of the total $\left(\Delta P_{\text {Total }}\right)$, friction $\left(\Delta P_{\text {Friction }}\right)$, piston $\left(\Delta P_{\text {Piston }}\right)$, and tip $\left(\Delta P_{\text {Tip }}\right)$ at various velocities of presses; $8.3 \times 10^{-5}, 8.3 \times 10^{-4}, 1.7 \times 10^{-3}$, and $3.3 \times 10^{-3} \mathrm{~m} / \mathrm{s}$, (left): air; (right): hemp oil.

Four nozzle tip sizes of $2.0 \times 10^{-4}, 4.0 \times 10^{-4}, 7.5 \times 10^{-4}$, and $1.0 \times 10^{-3} \mathrm{~m}$ radius were used for power booster outlet experiments (Figure 1); the VD method was applied. In Figure 4 (left), when the size of the commonly used tip was increased, many variables such as viscosity, flow rate, temperature, and shear stress of the material were assumed as constants. According to the HP theory equation, the $\Delta P_{\text {Tip }}$ or $\Delta P_{\text {Piston }}$ is inversely proportional to the 4 th power of the $\mathrm{r}_{\text {Tip }}$ or $\mathrm{r}_{\text {Piston, }}$, respectively. It was confirmed that when air was used as an experiment, the $\Delta P_{\text {Tip }}$ was reduced to the inverse of the radius of the tip $\left(\mathrm{r}_{\mathrm{Tip}}\right)$ to the power of 3.928. This idea made it possible to control the shear rate for quantitative extraction of the material while using a nozzle of an appropriate size. The rTip was $1.0 \times 10^{-3} \mathrm{~m}$ then decreased to $2.0 \times 10^{-4} \mathrm{~m}$. It was difficult to constantly control quantitative discharge in the case of using tips $2.0 \times 10^{-4}$ and $4.0 \times 10^{-4} \mathrm{~m}$. This problem was confirmed as the effect was much greater when hemp oil had a relatively high viscosity (Figure 4 , right). As the tip size decreased, the $\Delta P_{\text {Friction }}$ increased slightly, but the $\Delta P_{\text {Tip }}$ increased steeply. In the case of using a tip smaller than the size $2.0 \times 10^{-4} \mathrm{~m}$, the $\Delta P_{\text {Tip }}$ of the high-viscosity material itself seems to be a much bigger problem than the pressure caused by the $\Delta P_{\text {Friction. Th }}$. This concept is important in using a variety of materials and precise CBD controls with large variability. In the presence of high-viscosity liquids and solids, it was confirmed that constant discharge was possible under constant pressure reduction by applying the appropriate tip size and shear stress through the HP theory. The concept of quantitative CBD discharge has been understood and applied to telecare or telemedicine systems. Through repeated experiments, tele-delivery has been realized with 
a constant flow. Furthermore, the discharge flow rate change was maintained in the range of $\pm 0.3 \%$ by weight. Using the HP equation, the study aimed to find an initial 180-s safety and stability without any change in weight flow with CBD-infused foods. Note that even if it is not a Newtonian material, it can be successfully discharged as a high-viscosity food with a constant flow. No additional vacuum packaging or treatment was applied to save time and keep the ingredients fresh.
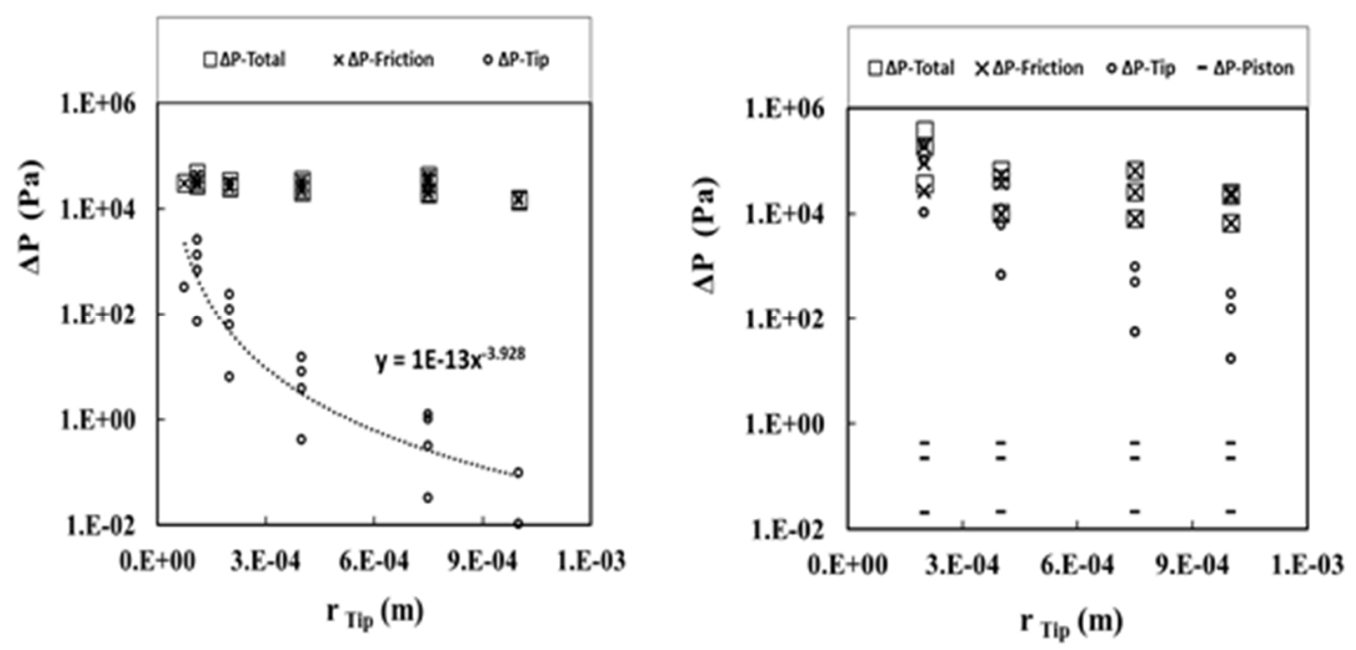

Figure 4. Pressure drop of total $\left(\Delta P_{\text {Total }}\right)$, friction $\left(\Delta P_{\text {Friction }}\right)$, piston $\left(\Delta P_{\text {Piston }}\right)$, and tip $\left(\Delta P_{\text {Tip }}\right)$ at various tip size in radius $\left(\mathrm{r}_{\text {Tip }}\right) ; 2.0 \times 10^{-4}, 4.0 \times 10^{-4}, 7.5 \times 10^{-4}$, and $1.0 \times 10^{-3} \mathrm{~m}$, (left): air; (right): hemp oil.

All tests were equipped with pistons filled with high viscosity materials such as SC processed CBD-infused foods and contaminated air or materials other than pistons, tips, and materials were prevented from entering the spaces within the equipment occupied the isolation system as described in Figure 1.

The most important process for telemedicine is to control the discharge linear velocity at which the material is discharged constantly by remotely controlling and applying a force beyond the total pressure drop $\left(\Delta P_{\text {Total }}\right)$. To expel air quantitatively (no material), it was found that the frictional force between the piston head and the inner wall of the piston was more affected than the relationship between tip and material (Figure 5). Therefore, it can be seen that as the shear rate applied to the materials increased, the rate at which materials were discharged flowed constantly, and the shear rate increased by measuring the linear velocity. In the case of printing, in which air and gas or air and liquid react as a whole, it was confirmed that constant discharge was possible under the pressure control. The concept of quantitative discharge was understood and applied to telemedicine. Quantitative dispensing without material provides basic information for constant dispensing of materials, including CBD, and in particular, remote treatment is possible by selecting a tip size that controls the $\Delta P_{\text {Total }}$.

For continuous discharge, six different materials were controlled remotely, and constant speed discharge for $5 \mathrm{~min}$ was successful. The detailed pressure and material preparation used in this study are included in the patents [10,42]. CBD-infused food can be discharged through automatic force control that overcomes the mentioned pressure drop. The power booster system (in Figure 1) controlled the force on the piston in the range of 5 to $170 \mathrm{~N}$. The most critical part of delivering food containing CBD in an untact manner is to stabilize the system and to provide the correct amount in a quick and simple form, as shown in Figure 6. Volumetric discharge vs. time, using various foods and VD design output images to control CBD content, is shown in Figure 6A: Cafe Box Delight (Café) logo with choco-pudding (cafeboxd.com); B: UT Austin emblem made from beef; C: bee design with ketchup; D: pelican design using CBD printed remotely. 


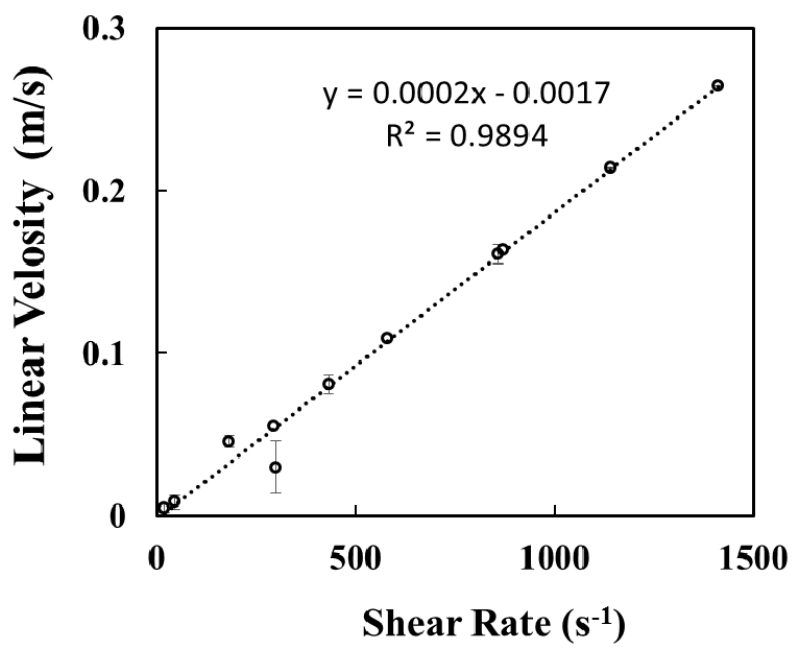

Figure 5. Linear velocity vs. various shear rates of the piston-type extruder for Air.

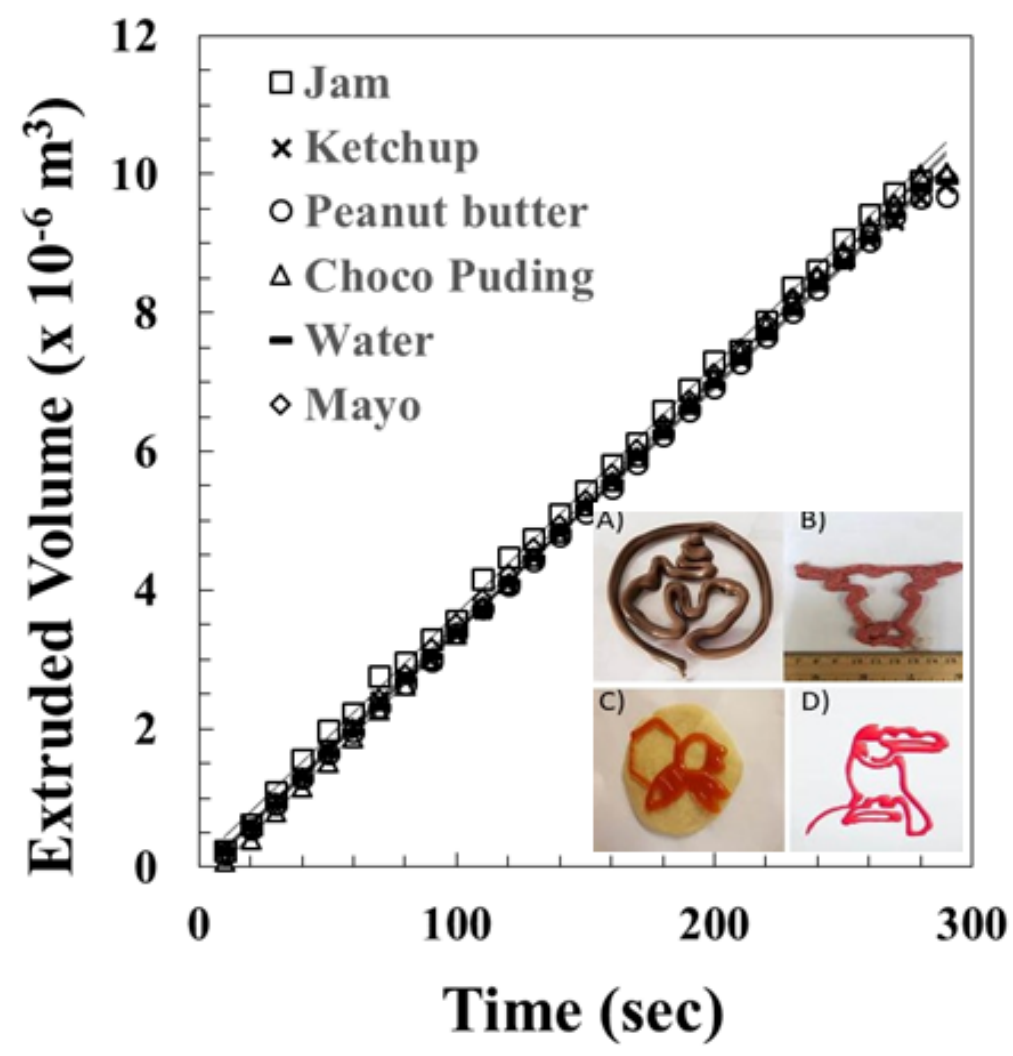

Figure 6. Volumetric discharge according to various foods and VD design output images to control CBD content; (A): Cafe Box Delight (Café) logo with choco-Pudding (cafeboxd.com) (B): UT Austin emblem made from beef; (C) bee design with ketchup; (D): pelican design using CBD injection ketchup.

\subsection{Vizo design (VD) to Keep Food Fresh}

The air exposure time is the variable that needs to be optimized to a minimum for telemedicine to maximize the anti-oxidation potential of CBD. By applying the continuous printing of VD, a caricature does not lose the artistic elements. VD has been applied to prohibit a sharp decline at specific points on the 3D printable model. If VD is not involved, the extrusion of the material at the deceleration point results in food build-up as CBD releases the injected food $[18,19]$. Conventional extrusion techniques did not work ideally for discharges with viscosities above $2000 \mathrm{~Pa}$ s, such as pizza dough. Piston 
printing technology was difficult to apply pressure to overcome adhesion, which led to inaccurate printing $[43,44]$. Three-dimensional food printing using PTE and STE (ScrewType Extruder) methods has a reproducibility problem of printing continuous quantities without VD [45]. Conventional printing with the PTE method is performed through a stopand-go process that repeats 10 to 1000 times. Many other studies have proposed mechanical solutions to solve this problem, such as increasing print speed or reducing friction $[30,31]$. VD can be utilized as a process for continuous discharge and fluent food flows continuously. VD technology allows for the quantitative control of CBD-infused food products extruded from the nozzle. The design idea had to be adjusted to improve the accuracy and printing performance of high-viscosity foods at any given time without losing their artistic value. When using liquid foods, simple caricatures are formed in one line that can express specific characteristics. The head traveling speed and linear velocity of the discharged CBD-infused food must match so that the contents are not overloaded or depleted. Many attempts have been made to optimize various viscosities of printing conditions and VD methods using VD and G code conversion for CBD-infused food. A system was capable of printing in a short time with the VD method that optimally prevented oxidation.

Due to the high level of nutritional and structural control over meat ingredients, telemedicine technology using PTE has proven to be a useful method for developing food ingredients and recipes. VD technology reduces printing time and reduces the time during which the material reacts with air. Using this untact printing technology, CBDinfused foods were 3D printed with a viscosity of $2000 \mathrm{~Pa}$ s, controlling the freshness of the food. Applying VD to an efficient PTE that accurately controls the exact amount of food ingredients can be effective without air oxidation of reaction-sensitive CBD. When using VD technology for high viscosity food materials, the print head can minimize overlapping distances and material unevenness caused by stop-and-go. For the same reason, it was useful to control the amount of final CBD by making continuous lines that do not break during printing. VD has been successfully applied, as shown in Figure 7 below, increasing the accuracy and printing efficiency of high-viscosity materials and preserving artistic value. With liquid food, the exact amount of CBD is controlled by creating a good substance representing the food itself in a single line. The pressure applied to the material and the head speed needs to be adjusted, controlled, and modified to print optimal discharge conditions in a short time $[9,29,30]$.

As seen in Figure 7, there were no flaws in designing the various shapes in one row. VD techniques using commonly used letters or logos have been reported in previous studies [33,34]. Works of world-renowned painters have been reinterpreted and reproduced in VD. Artistic or caricature designs containing CBD can be comfortably eaten by the elderly or children, while the options for remote delivery are unlimited.

This problem also occurs when the $\mathrm{z}$-axis does not switch between layers due to the collapse of the 3D structure and the inability to print ultra-high viscosity materials, and a great deal of effort has been put into integrating design and engineering techniques. Rhinoceros 3D was used to create VD designs and print 3D images [46]. These designs have been converted to $G$ code using open sources such as Cura [47]. A layer was deposited on top of food to manage the telemedicine using the method of using other open-source programs. From a designer's perspective, 3D VD can be a new concept of creation, and existing works can be recreated quickly. VD applicability has been confirmed through more than 3000 geometric experiments that are simple in the engineer's perspective but not artistically simple, where no point has to be passed twice. After completing the design file and using Cura, an open-source $\mathrm{G}$ transcoding program, the fill density was adjusted to $0 \%$ to support the overall structure. The basic design in Figure 7 shows a model of the VD design concept for controlling the accurate print volume emission and image of the function. Effective VD methods can be applied to transform 3D sculptures into 2D VD drawings to control the CBD contents. 

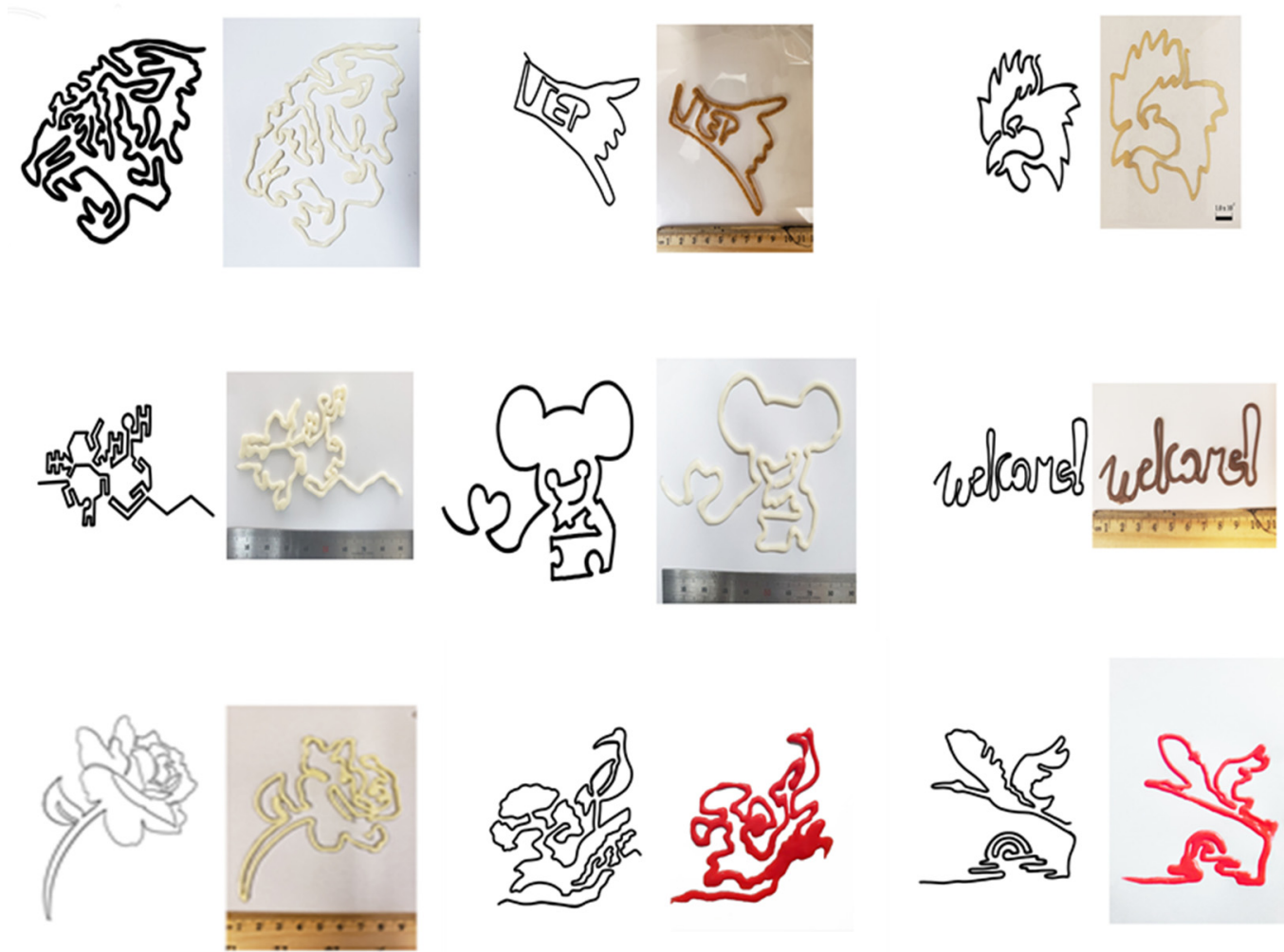

Figure 7. CBD-infused food VD printing work, telemedicine equipment, and quantitative control and artistic creation.

\subsection{Web-Based IoT Control}

A chicken sandwich, nail-sized hamburger, CBD-infused avocado sandwich, and various $2.5 \mathrm{D}$ and $3 \mathrm{D}$ structures were printed using high-precision PTE in less than $1 \mathrm{~min}$ using an IoT controller via the web. The isolated printing space is temperature-controlled, as shown in Figure 1 in the area where the air is blocked and divided into internal and external atmosphere. The VD file is uploaded to the web. Untact telemedicine systems (currently four are located in Seoul, Korea University and eight are located in El Paso, UTEP) with video, text, and G-Code related images are immediately transmitted to the other country's system after selection. People receive videos, text, and notifications through social media, and when they are authenticated on the site, the other party receives the final CBD food. This system is designed to be provided to doctors and pharmacists.

As shown in Figure 8, various CBD-infused food was printed in 2D or 3D on top of bread, cookies, or salad. It is an option to print SC- $\mathrm{CO}_{2}$ beef, which could be customized by CBD-infused 3D foods and other ingredients. The stability and accuracy of the CBD-infused food was consistent until the head speed was increased to $1.6 \times 10^{-2} \mathrm{~m} / \mathrm{s}$. The accuracy of printing materials from the corners of the pattern was unstable when the printing speed exceeded $1.6 \times 10^{-2} \mathrm{~m} / \mathrm{s}$. Three-dimensional shapes effectively printed within $10 \mathrm{~min}$ and stacked over 20 layers using a PTE 3D printer have reported that the STE method can be performed effectively in one area, whereas the PTE method cannot proceed without post-treatment of high-viscosity materials [27].

Two to five layers were stacked in 2D or 3D for 2 min to maintain the CBD-infused food shapes as exhibited in Figure 8. A chocolate (A), cookie dough (F-H), and pizza dough (I and K) were each successfully printed. Web-platform-based IoT-controlled, non-face-toface contact technology was successfully applied to make the words, and caricatures were also successfully printed in 2.5D using (B) choco-mousse, (C) ice cream, and (D) yogurt. In the case of the pizza dough, whose 3D shape was difficult to maintain due to the moisture content of the material and swelling, it was printed in various artworks and held the shapes without any problem for up to 30 layers [30,34]. The amount discharged ranged from 12 to 
$50 \mathrm{~g}$ within $10 \mathrm{~min}$ in the 3D STE printed shape. Due to the materials being soft and easy to deform, it was challenging to maintain the 3D shape of porous and soft CBD-infused foods. The regulation of CBD depends on the country, so all samples produced were discarded immediately after filming.
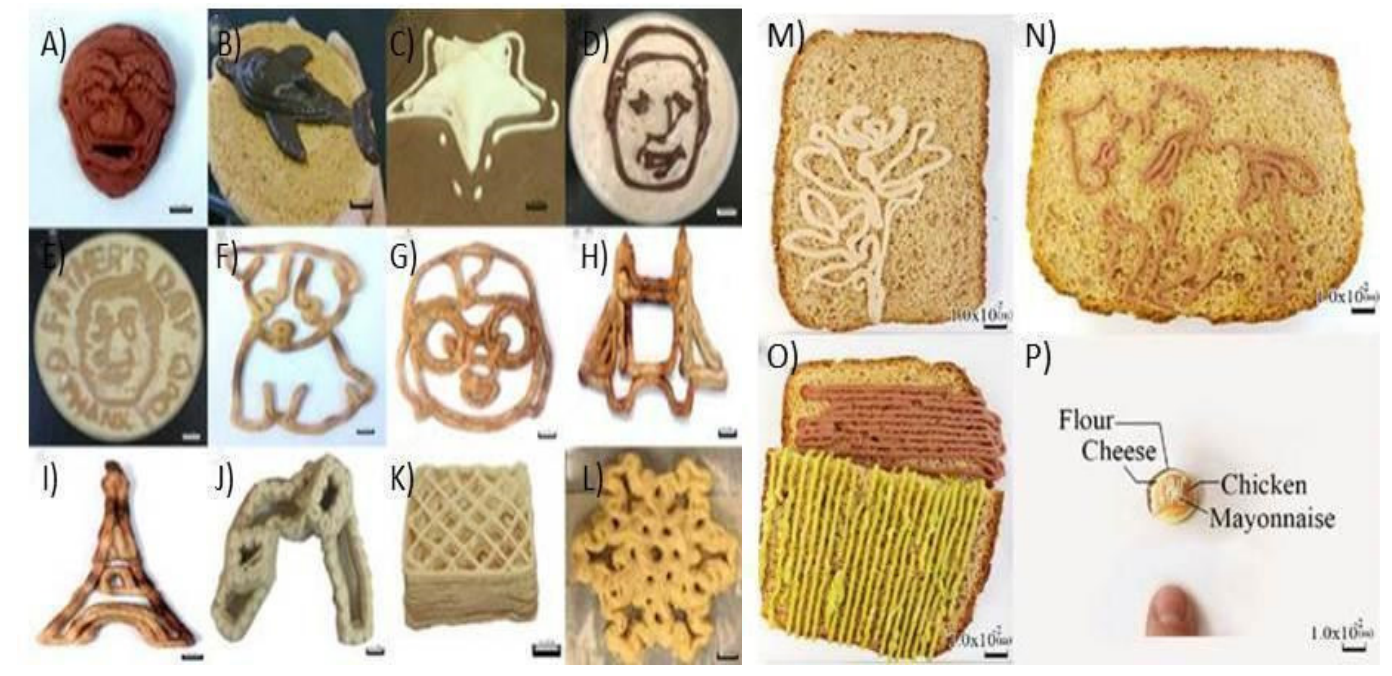

Figure 8. Various types of 2.5D and 3D foods and their PTE or STE conditions. (A): 3D STE chocolate chip, (head speed $1.8 \times 10^{-2} \mathrm{~m} / \mathrm{s}$ and tip size $\left.2.0 \times 10^{-3} \mathrm{~m}\right)$; $(\mathbf{B})$ : 3D STE choco-pudding, (head speed $3.6 \times 10^{-2} \mathrm{~m} / \mathrm{s}$ and tip size $\left.2.0 \times 10^{-3} \mathrm{~m}\right) ;(\mathbf{C})$ : 3D STE ice-cream (head speed $1.8 \times 10^{-2}$ $\mathrm{m} / \mathrm{s}$ and tip size $2.0 \times 10^{-3} \mathrm{~m}$ ); (D): $2 \mathrm{D}$ PTE yogurt, (head speed $7.2 \times 10^{-2} \mathrm{~m} / \mathrm{s}$ and tip size $5.0 \times$ $\left.10^{-4} \mathrm{~m}\right) ;\left(\right.$ E): 2D PTE yogurt, (head speed $2.4 \times 10^{-2} \mathrm{~m} / \mathrm{s}$ and tip size $\left.5.0 \times 10^{-4} \mathrm{~m}\right) ;(\mathbf{F})$ : 2D STE cookie-dough, (head speed $2.4 \times 10^{-2} \mathrm{~m} / \mathrm{s}$ and tip size $\left.2.0 \times 10^{-3} \mathrm{~m}\right) ;(\mathrm{G}): 2 \mathrm{D} \mathrm{STE}$ cookie-dough, (head speed $2.4 \times 10^{-2} \mathrm{~m} / \mathrm{s}$ and tip size $2.0 \times 10^{-3} \mathrm{~m}$ ); $(\mathbf{H})$ : 3D STE cookie-dough, (head speed 2.4 $\times 10^{-2} \mathrm{~m} / \mathrm{s}$ and tip size $\left.2.0 \times 10^{-3} \mathrm{~m}\right) ;(\mathrm{I}): 2 \mathrm{D}$ STE pizza-dough, (head speed $2.4 \times 10^{-2} \mathrm{~m} / \mathrm{s}$ and tip size $\left.2.0 \times 10^{-3} \mathrm{~m}\right) ;(\mathrm{J})$ : $3 \mathrm{D}$ STE pizza-dough, (head speed $3.6 \times 10^{-2} \mathrm{~m} / \mathrm{s}$ and tip size $2.0 \times 10^{-3}$ $\mathrm{m}) ;(\mathbf{K})$ : 3D STE pizza-dough, (head speed $1.8 \times 10^{-2} \mathrm{~m} / \mathrm{s}$ and tip size $\left.2.0 \times 10^{-3} \mathrm{~m}\right) ;(\mathrm{L})$ : 3D STE cookie-dough, (head speed $7.2 \times 10^{-2} \mathrm{~m} / \mathrm{s}$ and tip size $\left.2.0 \times 10^{-3} \mathrm{~m}\right) ;(\mathbf{M})$ : 2D PTE CBD-infused chicken, (head speed $1.8 \times 10^{-2} \mathrm{~m} / \mathrm{s}$ and tip size $\left.1.0 \times 10^{-3} \mathrm{~m}\right) ;(\mathrm{N}): 2 \mathrm{D}$ PTE CBD-infused beef using SC- $\mathrm{CO}_{2}$, (head speed $1.8 \times 10^{-2} \mathrm{~m} / \mathrm{s}$ and tip size $\left.1.0 \times 10^{-3} \mathrm{~m}\right) ;(\mathbf{O}): 2 \mathrm{D}$ PTE CBD-infused avocado sandwich with treated beef using SC- $\mathrm{CO}_{2}$ (head speed $1.8 \times 10^{-2} \mathrm{~m} / \mathrm{s}$ and tip size $1.0 \times 10^{-3} \mathrm{~m}$ ) and CBD-infused avocado (head speed $1.8 \times 10^{-2} \mathrm{~m} / \mathrm{s}$ and tip size $1.0 \times 10^{-3} \mathrm{~m}$ ); (P): 2D PTE CBD-infused chicken burger; flour dough (head speed $1.8 \times 10^{-2} \mathrm{~m} / \mathrm{s}$ and tip size $1.0 \times 10^{-3} \mathrm{~m}$ ), cheese (head speed $7.0 \times 10^{-3} \mathrm{~m} / \mathrm{s}$ and tip size $3.2 \times 10^{-4} \mathrm{~m}$ ), chicken (head speed $7.0 \times 10^{-3} \mathrm{~m} / \mathrm{s}$ and tip size $3.2 \times 10^{-4} \mathrm{~m}$ ) and mayonnaise (head speed $7.0 \times 10^{-3} \mathrm{~m} / \mathrm{s}$ and tip size $1.1 \times 10^{-4} \mathrm{~m}$ ).

In Figure 8M,N, both designs (rose and "Angry Ox") were applied at the head speed of $1.8 \times 10^{-2} \mathrm{~m} / \mathrm{s}$ with a tip size of $1.0 \times 10^{-3} \mathrm{~m}$. In advance, printing the rose design with CBD-infused chicken on bread discharged $1.40 \mathrm{~g}$ in $120 \mathrm{~s}$. Subsequently, the "Angry Ox" design with $\mathrm{SC}-\mathrm{CO}_{2}$ beef printed $0.93 \mathrm{~g}$ in $84 \mathrm{~s}$. Figure $8 \mathrm{O}$ shows a $2.5 \mathrm{D}$ printed sandwich with $\mathrm{SC}-\mathrm{CO}_{2}$ beef and $\mathrm{CBD}$-infused avocado. The printing process was implemented at the head speed of $1.8 \times 10^{-2} \mathrm{~m} / \mathrm{s}$ with a tip size of $1.0 \times 10^{-3} \mathrm{~m}$. The small size of cheeseburger was printed using cheese, chicken, flour dough, and CBD-infused mayonnaise (Figure $8 \mathrm{P}$ ). All of the foods have their optimum conditions that were successfully applied to construct the small size of cheeseburger (flour dough: head speed $1.8 \times 10^{-2} \mathrm{~m} / \mathrm{s}$ and tip size $1.0 \times$ $10^{-3} \mathrm{~m}$, cheese: head speed $7.0 \times 10^{-3} \mathrm{~m} / \mathrm{s}$ and tip size $3.2 \times 10^{-4} \mathrm{~m}$, chicken: head speed $7.0 \times 10^{-3} \mathrm{~m} / \mathrm{s}$ and tip size $3.2 \times 10^{-4} \mathrm{~m}$, and mayonnaise: head speed $7.0 \times 10^{-3} \mathrm{~m} / \mathrm{s}$ and tip size $1.0 \times 10^{-4} \mathrm{~m}$ ). 


\section{Conclusions}

With the recent COVID-19 pandemic, the necessity of an untact and remote delivery system has gained a rapid social response. It is a result of food 3D experiments focused on non-face-to-face or untact, web-based equipment control, security, and telemedicine technology using CBD with food. The IoT-enabled printers, utilizing single-line designs and basic 3D structures developed by artistic collaborators for these applications, have proven to be especially useful for evaluating the potential of materials by this method. Vizo design evaluations following a gridline format allow for very reliable determinations of printer head speed. In contrast, the simple 3D geometries allow for the assessment of layer thicknesses and structural stability while not on the print bed. Earlier works demonstrate that even while printing with materials exhibiting non-Newtonian rheological properties, printing conditions could be optimized to find linear regions within curves generated via the Hagen-Poiseuille equation such that an ideal flow may be found for a specific amount of time. Prints with meat base materials have been shown to have their optimal print parameters at a head speed of $1.8 \times 10^{-2} \mathrm{~m} / \mathrm{s}$ for $110 \mathrm{~s}$ using a $3.2 \times 10^{-4} \mathrm{~m}$ head tip. The repeated experiments showed the precision of material deposition of $0.2 \mathrm{wt} \%$. With $3 \mathrm{D}$ structures, this head speed is reduced to $7.0 \times 10^{-3} \mathrm{~m} / \mathrm{s}$. It was possible to produce recognizable shapes based on CAD designs using food materials without interference from the printability issues that commonly arise when printing with high viscosity materials.

After SC- $\mathrm{CO}_{2}$, the porridge-like food materials have an issue maintaining 3D structure. The experimental results proved that the PTE telemedicine method has the advantage of structural formation using slurry materials with CBD. The telemedicine method has superior power in nutrition maintenance and oxidation prevention based on low energy processing. Moreover, the technology has the flexibility of printing not only meat but sushi and vegetables as well. Printing CBD-infused beef treated with $\mathrm{SC}-\mathrm{CO}_{2}$ opens the novel direction of providing hygienic foods directly to customers with a precise amount of nutrition. Three-dimensional printed food materials have a structural advantage for the cooking process because of the thin layer-by-layer design. A structure that contains a similar composition through material processing contributes to low cooking heat recipes, which contain sensitive medicines such as CBD, by dispersing heat energy efficiently. The amalgamation of $3 \mathrm{D}$ printing and IoT has opened a new chapter in telemedicine. Research is needed to explore an innovative approach to delivering a wide range of drugs through this method.

Author Contributions: Conceptualization, N.P.K.; methodology, N.P.K. and A.A.; software, N.P.K.; validation, N.P.K., A.A., H.-j.K.; H.-D.P.; formal analysis, A.A.; investigation, H.-j.K. and H.-D.P.; resources, N.P.K.; data curation, A.A.; writing—original draft preparation, N.P.K. and A.A.; writingreview and editing, A.A.; visualization, N.P.K.; supervision, N.P.K.; project administration, N.P.K.; funding acquisition, N.P.K. All authors have read and agreed to the published version of the manuscript.

Funding: The Korean Research Foundation's Brain Pool Fellowship Program, (2020H1D3A2A02085514).

Institutional Review Board Statement: Not applicable.

Informed Consent Statement: Not applicable.

Acknowledgments: This study was supported by the Korean Research Foundation's Brain Pool Fellowship Program, Development of a Non-Face-to-Face CBD Telemedicine System (2020H1D3A2A0208 5514).

Conflicts of Interest: The authors declare no conflict of interest.

Ethics Statement: This research did not include any human subjects or animal experiments.

\section{References}

1. Salami, S.A.; Martinelli, F.; Giovino, A.; Bachari, A.; Arad, N.; Mantri, N. It Is Our Turn to Get Cannabis High: Put Cannabinoids in Food and Health Baskets. Molecules 2020, 25, 4036. [CrossRef]

2. Cerino, P.; Buonerba, C.; Cannazza, G.; D’Auria, J.; Ottoni, E.; Fulgione, A.; Di Stasio, A.; Pierri, B.; Gallo, A. A Review of Hemp as Food and Nutritional Supplement. Cannabis Cannabinoid Res. 2021, 6, 19-27. [CrossRef] 
3. Tamba, B.I.; Stanciu, G.D.; Urîtu, C.M.; Rezus, E.; Stefanescu, R.; Mihai, C.T.; Luca, A.; Rusu-Zota, G.; Le-on-Constantin, M.M.; Cojocaru, E.; et al. Challenges and opportunities in preclinical research of synthetic cannabinoids for pain therapy. Medicine 2020, 56, 24. [CrossRef] [PubMed]

4. Tocris Bioscience. Available online: https://www.tocris.com/products/minus-cannabidiol_1570\#product-details (accessed on 1 November 2019).

5. Fraguas-Sánchez, A.I.; Fernández-Carballido, A.; Martin-Sabroso, C.; Torres-Suárez, A.I. Stability characteristics of cannabidiol for the design of pharmacological, biochemical and pharmaceutical studies. J. Chromatogr B Anal. Technol Biomed. Life Sci. 2020, 1150, 122188. [CrossRef]

6. Gaoni, Y.; Mechoulam, R. Hashish-VII: The isomerization of cannabidiol to tetrahydrocannabinol. Tetrahedron 1966, 22, 1481-1488. [CrossRef]

7. Mechoulam, R.; Hanus, L. Cannabidiol: An overview of some chemical and pharmacological aspects. Part I: Chemical aspects. Chem. Phys. Lipids 2002, 121, 35-43. [CrossRef]

8. Watanabe, K.; Itokawa, Y.; Yamaori, S.; Funahashi, T.; Kimura, T.; Kaji, T.; Usami, N.; Yamamoto, I. Conversion of cannabidiol to $\Delta$ 9-tetrahydrocannabinol and related cannabinoids in artificial gastric juice, and their pharmacological effects in mice. Forensic Toxicol. 2007, 25, 16-21. [CrossRef]

9. Bonn-Miller, M.O.; Banks, S.L.; Sebree, T. Conversion of Cannabidiol FollowingOral Administration: Authors' Response to Grotenhermenetal. Cannabis Cannabinoid Res. 2017, 2, 5-7. [CrossRef]

10. Kim, N. 3D Printed CBD Inclusive Object and Its Operation System. PCT/KR2020/007759, 20 May 2021.

11. Consroe, P.; Laguna, J.; Allender, J.; Snider, S.; Stern, L.; Sandyk, R.; Kennedy, K.; Schram, K. Controlled clinical trial of cannabidiol in Huntington's disease. Pharmacol. Biochem. Behav. 1991, 40, 701-708. [CrossRef]

12. Sun, J.; Zhou, W.; Yan, L.; Huang, D.; Lin, L.Y. Extrusion-Based Food Printing for Digitalized Food Design and Nutrition Control. J. Food Eng. 2018, 220, 1-11. [CrossRef]

13. Yang, F.; Zhang, M.; Bhandari, B. Recent Development in 3D Food Printing. Crit. Rev. Food Sci. Nutr. 2015, 57, 3145-3153. [CrossRef]

14. Liu, Z.; Zhang, M.; Bhandari, B.; Yang, C. Impact of Rheological Properties of Mashed Potatoes on 3D printing. J. Food Eng. 2018, 220, 76-82. [CrossRef]

15. Tohic, C.L.; O'Sullivan, J.J.; Drapala, K.P.; Chartrin, V.; Chan, T.; Morrison, A.P.; Kerry, J.P.; Kelly, A.L. Effect of 3D printing on the Structure and Textural Properties of Processed Cheese. J. Food Eng. 2018, 220, 56-64. [CrossRef]

16. Eo, J.S.; Cepeda, B.; Kim, J.H.; Kim, N.S. A New Paradigm of Pharmaceutical Drug Delivery Systems (DDS): Challenges for Distance, Time, and Shapes. Innov. Pharm. 2018, 9, 11-24.

17. Cogan, P.S. Reality and Legality: Disentangling What Is Actual from What Is Tolerated in Comparisons of Hemp Extracts with Pure CBD. J. Diet. Suppl. 2020, 17, 1-16. [CrossRef]

18. Kim, S.J.; Kim, J.H.; Cepeda, B.; Kim, N.S. Single Line Design Technique to Improve the Accuracy of Drug Delivery System: Piston Type Extrusion. In Proceedings of the International Conference on Computational Science and Computational Intelligence (CSCI), Las Vegas, NV, USA, 12-14 December 2018; pp. 709-714.

19. Kim, N.P.; Cepeda, B.; Kim, J.; Yue, G.; Kim, S.; Kim, H. IoT Controlled Screw-Type 3D Food Printer Using Single Line Design Technique. In Proceedings of the International Conference on Computational Science and Computational Intelligence (CSCI), Las Vegas, NV, USA, 12-14 December 2018; pp. 978-983.

20. Cafe Box Delight. Available online: https://www.cafeboxd.com (accessed on 1 September 2019).

21. Kim, N.P.; Eo, J.S.; Cho, D. Optimization of Piston Type Extrusion (PTE) techniques for 3D Printed Food. J. Food Eng. 2018, 235, 41-49. [CrossRef]

22. Taylor-Black, S.; Wang, J. Prevalence of Food Allergy in Urban Children. J. Allergy Clin. Immunol. 2012, 109, 431-437. [CrossRef]

23. Kouzani, A.Z.; Adams, S.; Whyte, D.J.; Oliver, R.; Hemsley, B.; Palmer, S.; Balandin, S. 3D Printing of Food for People with Swallowing Difficulties. KnE Eng. 2017, 2, 23. [CrossRef]

24. Octoprint. Available online: https:/ / octoprint.org/ (accessed on 1 September 2019).

25. Alvarado, C.; McKee, S. Marination to improve functional properties and safety of poultry meat. J. Appl. Poult. Res. 2007, 16, 113-120. [CrossRef]

26. Ashraf-Khorassani, M.; Gidanian, S.; Yamini, Y. Effect of Pressure, Temperature, Modifier, Modifier Concentration, and Sample Matrix on the (SC-CO2) Fluid Extraction Efficiency of Different Phenolic Compounds. J. Chrom. Sci. 1995, 33, 658-662. [CrossRef]

27. Wehling, R.L.; Froning, G.W.; Cuppett, S.L.; Niemann, L. Extraction of Cholesterol and Other Lipids from Dehydrated Beef Using (SC-CO2) Carbon Dioxide. J. Agric. Food Chem. 1992, 40, 1204-1207. [CrossRef]

28. Chung, S.; Kwon, H.; Kim, N.P. Supercritical extraction of decellularized extracellular matrix from porcine adipose tissue as regeneration therapeutics. J. Cosm. Med. 2019, 3, 86-93. [CrossRef]

29. Raventós, M.; Duarte, S.; Alarcón, R. Application and Possibilities of (SC-CO $\left.\mathrm{CO}_{2}\right) \mathrm{CO}_{2}$ Extraction in Food Processing Industry: An Overview. Food Sci. Technol. Int. 2002, 8, 269-284. [CrossRef]

30. Roy, B.C.; Goto, M.; Hirose, T. Extraction of Ginger Oil with $\left(\mathrm{SC}_{-} \mathrm{CO}_{2}\right)$ Carbon Dioxide: Experiments and Modeling. Ind. Eng. Chem. Res. 1996, 35, 607-612. [CrossRef]

31. Martha, Y.L.R.; Alma, D.A.R.; Timothy, J.M.; Larysa, P.; Mohammed, A. Ultrasound-Enhanced Mass Transfer in Halal Compared with Non-Halal Chicken. J. Sci. Food Agric. 2010, 91, 130-133. 
32. Aziz, Y.A.; Chok, N.V. The Role of Awareness, Certification, and Marketing Components in Determining Purchase Intention Among Non-Muslims in Malaysia: A Structural Equation Modeling Approach. J. Int. Food Agribus. Mark. 2013, 25, 1-23. [CrossRef]

33. Ismail, A.G.; Mohd-Noor, M.A. Finance and Foods: Are They Falling Apart? Acta Uni.s Dan. Oecon. 2016, 3, 113-126.

34. Mumuni, A.G.; Veeck, A.; Luqmani, M.; Quraeshi, Z.A.; Kamarulzaman, Y. Religious Identity, Community and Religious Minorities' Search Efforts for Religiously Sanctioned Food: The Case of Halal Food in Non-Muslim Majority Markets. Int. J. Consum. Stud. 2018, 42, 586-598. [CrossRef]

35. Zailani, S.; Arrifin, Z.; Wahid, N.A.; Othman, R.; Fernando, Y. Traceability and Tracking Systems in Strengthening Food Supply Chain for Food Industry in Malaysia (A Review). J. Food Technol. 2010, 8, 74-81.

36. Nakyinsige, K.; Fatimah, A.B.; Aghwan, Z.A.; Zulkifli, I.; Goh, Y.M.; Sazili, A.Q. Bleeding Efficiency and Meat Oxidative Stability and Microbiological Quality of New Zealand White Rabbits Subjected to Halal Slaughter without Stunning and Gas Stun-Killing. Asian-Australasian, J. Anim. Sci. 2014, 27, 406-413. [CrossRef]

37. Saracin, V.C. The Food Law in Malaysia. Contemp. Read. Law Soc. Justice 2017, 2, 372-382.

38. Sungkar, I. The global Halal trade, trends and issues. Halal J. 2008, 3, 32-34.

39. Talib, M.S.A.; Sawari, S.S.M.; Hamid, A.B.A.; Chin, T.A. Emerging Food Market: An Institutional Theory of Certificate Implementation. Manag. Res. Rev. 2016, 39, 987-997. [CrossRef]

40. Openmeals. Available online: https:/ / www.open-meals.com (accessed on 1 September 2019).

41. White, C.M. A Review of Human Studies Assessing Cannabidiol's (CBD) Therapeutic Actions and Potential. J. Clin. Pharmacol. 2019, 59, 923-934. [CrossRef]

42. Kim, N. Method for Manufacturing Liquid Containing CBD and Telemedicine System Providing CBD Infused Foods. KR10-20210054391, 27 April 2020.

43. Hoffman, J.; Hwang, S.Y.; Ortega, A.; Kim, N.S.; Moon, K.S. The Standardization of Printable Materials and Direct Writing Systems. J. Elect. Pack. 2013, 135, 011006-13. [CrossRef]

44. Kim, N.S.; Han, K.N.; Church, K.H. Direct Writing Technology for 21st Century Industries-Focus on Micro-Dispensing Deposition Write Technology. J. KSMTE. 2007, 5, 511-515.

45. Hong, S.; Kim, N.S. Synthesis of 3D Printable Cu-Ag Core-shell Materials- Kinetics of CuO Film Removal. J. Elec. Mater. 2015, 44, 823-830. [CrossRef]

46. Rhinos. Available online: https:/ / www.rhino3d.com (accessed on 1 June 2019).

47. Ultimaker. Available online: https:/ / ultimaker.com (accessed on 1 October 2019). 